\title{
SIFAT-SIFAT DASAR PERLUASAN INTEGRAL LEBESGUE
}

(Basic Properties Of Extended Lebesgue Integral)

\author{
Yopi Andry Lesnussa, Henry Junus Wattimanela, Mozart Winston Talakua \\ Jurusan Matematika, FMIPA,Universitas Pattimura \\ Email : yopi_a_lesnussa@yahoo.com
}

\begin{abstract}
$E L$-Integral is extended of Lebesgue integral, $\quad(E L) \int_{a}^{b} f d \mu=\sum_{k=1}^{\infty}(L) \int_{\bar{I}_{k}} f d \mu$.
\end{abstract}

Lebesgue integral is defined with early arrange measure theory that famous with Lebesgue measure. A function $f:[a, b] \rightarrow \bar{\Re}$ is said $E L$-integrable on $[a, b]$, if there exist series interval that no piled up $\left\{I_{k}\right\}$ in $[a, b]$ so that $\mu\left([a, b]-\bigcup I_{k}\right)=0$, $f \in L\left(\bar{I}_{k}\right)$ for every $k$ and $A=\sum_{k=1}^{\infty}(L) \int_{\bar{I}_{k}} f d \mu$ finite. Value $A$ is called value of $E L$ Integral function $f$ on $[a, b]$. Extended of Lebesgue integral (EL-Integral) is notated by : $(E L) \int_{E} f d \mu=\int_{a}^{b} f d \mu=\sum_{k=1}^{\infty}(L) \int_{I_{k}} f d \mu$.

Keywords: Measure Space, Lebesgue Measure, Lebesgue Integral, Sifat-sifat Dasar EL-Integral.

\section{PENDAHULUAN}

Perkembangan analisis dimulai dengan penemuan Kalkulus oleh Newton dan Leibniz yang berhasil mengembangkan teorema fundamental yaitu mengenai antiderivatif. Salah satu konsep dasar dalam analisis adalah integral. Teori integral klasik dikembangkan oleh Cauchy dan Riemann pada pertengahan abad ke-19. Namun kekurangan dari integral Riemann ini muncul ketika proses integrasi dikenakan pada fungsi yang diskontinu, misalnya fungsi Dirichlet yang tidak terintegral Riemann. Untuk mengatasi kekurangan ini, pada tahun 1902, Lebesgue seorang matematikawan Perancis mendefinisikan integral Lebesgue dengan terlebih dahulu menyusun teori ukuran yang dikenal dengan Ukuran Lebesgue (pada garis lurus). Denjoy (1912) membangun teori integral dengan mencermati karakteristik kekontinuan fungsi primitifnya menghasilkan suatu integral yang disebut Integral Denjoy khusus. Perron (1914) membangun teori integralnya dengan mendasarkan pada pengertian fungsi mayor dan fungsi minor yang disebut Integral Perron . Pada tahun 1957-1960 Henstock dan Kurzweil secara terpisah dalam waktu hampir bersamaan mengembangkan integral jenis Riemann dengan mengubah peran konstanta positif $\delta$ pada konstruksi integral Riemann menjadi fungsi positif $\delta$ yang disebut dengan integral Riemann kontinu lengkap atau integral Henstock-Kurzweil (Integral-HK) (Soeparna 1999).

Telah diketahui bahwa meskipun integral Denjoy khusus, integral Perron dan integral- $H K$ mengitlakan sifat yang berbeda dari integral Lebesgue tetapi ketiga integral ini ekuivalen dan juga merupakan pengitlakan dari integral Lebesgue. Soeparna (1996) menyatakan bahwa posisi integral Lebesgue dalam integral- $H K$ adalah rapat (dense) terkendali, ini berarti bahwa untuk setiap fungsi $f$ yang terintegral- $H K$ terdapat barisan fungsi terintegral Lebesgue $\left\{f_{n}\right\}$ yang konvergen terkendali ke fungsi $f$.

Selanjutnya dengan mencermati sebuah fungsi yang tidak terintegral Lebesgue pada selang tertutup $[0,1]$ tetapi terintegral Lebesgue pada setiap selang bagiannya. Soeparna (1999) mendefinisikan sebuah integral baru yang disebut Perluasan integral Lebesgue (integral-EL). Berdasarkan pada uraian di atas maka peneliti tertarik untuk mendalami dan menganalisis secara mendetail mengenai bentuk dan sifat dasar dari integral-EL. Dalam penelitian ini, peneliti akan menggunakan definisi dan 
teorema serta teori matematika lain untuk menjelaskan permasalahan ini.

\section{TINJAUAN PUSTAKA}

Dalam perkembangan teori integral, sekitar abad ke20, Lebesgue mengembangkan teori ukuran dengan mengitlakan konsep panjang selang-selang ke dalam ukuran himpunan pada bilangan nyata (real). Ia mengembangkan teori integral dengan menggunakan ukuran Lebesgue (pada garis lurus), yang ditulis dalam naskah publikasinya yang berjudul Integral Longueur aire pada tahun 1902 (Jain, 1986). Selanjutnya integral tersebut dikembangkan menjadi integral Lebesgue yang bekerja pada ruang ukuran.

Sejalan dengan perkembangan teori integral, didalam pendefinisian secara deskriptif integral Lebesgue yang dibangun oleh Lebesgue memerlukan fungsi yang kontinu mutlak. Pada tahun 1912, A. Denjoy mendefinisikan integral Denjoy khusus dengan menggunakan fungsi kontinu yang sekaligus kontinu mutlak teritlak. Fungsi $F:[a, b] \rightarrow \mathfrak{R}$ dikatakan kontinu mutlak pada $x \subset[a, b]$, ditulis $F \in A C^{*}(x)$ dan $F$ dikatakan kontinu mutlak teritlak ditulis $F \in A C G^{*}(x)$. Terbukti bahwa fungsi $f:[a, b] \rightarrow \mathfrak{R}$ terintegral Lebesgue pada selang $[a, b]$ jika dan hanya jika terdapat fungsi $F:[a, b] \rightarrow \mathfrak{R}$ yang bersifat kontinu mutlak pada $[a, b]$ dan $F^{\prime}(x)=f(x)$ h.d. pada $[a, b]$.

Fungsi $f:[a, b] \rightarrow \Re$ terintegral-HK pada $[a, b]$ jika dan hanya jika terdapat fungsi $F:[a, b] \rightarrow \Re$ yang bersifat kontinu dan $A C G^{*}$ pada $[a, b]$ dan $F^{\prime}(x)=f(x)$ h.d. pada $[a, b]$. Oleh karena itu setiap fungsi yang terintegral Lebesgue pada selang $[a, b]$ akan terintegral- $H K$ juga pada selang yang sama. Telah diketahui bahwa Integral Denjoy khusus, integral Perron dan integral- $H K$ adalah berbeda dan ketiganya merupakan pengitlakan dari integral Lebesgue. Barisan fungsi $\left\{f_{n}\right\}$ dikatakan konvergen terkendali ke fungsi $f$ pada selang $[a, b]$ jika memenuhi syarat berikut : (i). $f_{n}$ terintegral- $H K$ pada $[a, b]$ dengan primitif $F_{n}$ untuk setiap $n$ dan barisan $\left\{f_{n}\right\}$ konvergen ke $f$ h.d. pada $[a, b]$, (ii). Barisan $\left\{F_{n}\right\}$ bersifat $A C G^{*}$ seragam pada $[a, b]$ dan (iii). $\left\{f_{n}\right\}$ konvergen, katakan ke $F$ pada. Selanjutnya posisi integral Lebesgue dalam integral- $H K$ adalah rapat (dense) terkendali. Ini berarti bahwa untuk setiap fungsi $f$ yang terintegral- $H K$ terdapat barisan fungsi yang terintegral Lebesgue $\left\{f_{n}\right\}$ yang konvergen terkendali ke fungsi $f$.

\section{Ukuran Lebesgue \\ Definisi 1 (Ukuran Lebesgue)}

Panjang suatu selang terbatas $I$ baik terbuka, tertutup, setengah terbuka atau setengah tertutup dengan titik pangkal $a$ dan titik ujung $b(a<b)$ didefinisikan sebagai bilangan $l(I)=|I|=b-a$. Pengertian ukuran suatu himpunan didefinisikan dengan menggunakan pengertian panjang selang.

\section{Definisi 2}

Jika $\mathscr{A}$ aljabar (aljabar- $\sigma$ ) pada himpunan $X$, dan aljabar- $\sigma$ himpunan $\mathscr{A} \subset 2^{X}$ disebut Ruang Terukur (measurable space), ditulis $(X, \mathscr{A})$. Dan anggota $\mathscr{A}$ disebut Himpunan Terukur (measurable set).

\section{Definisi 3}

Diberikan $(X, \mathscr{A})$ ruang terukur fungsi $\mu: \mathscr{A} \rightarrow \overline{\mathfrak{R}}$ disebut ukuran pada $X$ (measure) jika memenuhi aksiomaaksioma berikut :

$$
\begin{array}{ll}
\text { a. } & \mu(\phi)=0 \\
\text { b. } & \mu(A) \geq 0, \quad \forall A \in \mathscr{A} \\
\text { c. } \text { Jika }\left\{E_{k}\right\} \subset \mathscr{A} \text { dan } E_{k} \cap E_{l}=\phi, \\
\\
\forall k \neq l \text { berakibat } \mu\left(\bigcup_{k=1}^{\infty} E_{k}\right)=\sum_{k=1}^{\infty} \mu\left(E_{k}\right) .
\end{array}
$$

\section{Definisi 4}

Ruang terukur $(X, \mathscr{A})$ diperlengkapi dengan suatu ukuran $\mu$ disebut Ruang Ukuran (measure space) dan ditulis dengan $(X, \mathscr{A}, \mu)$.

\section{Definisi 5}

Diberikan himpunan $A \subseteq \mathfrak{R}$ dan $\mathfrak{I}$ menyatakan koleksi semua barisan selang terbuka $\left\{I_{n}\right\}$ sehingga $A \subseteq \bigcup_{n} I_{n}$. Ukuran luar himpunan $A$, ditulis $\mu^{*}(A)$ adalah bilangan

$$
\mu^{*}(A)=\inf \left\{\sum_{n} l\left(I_{n}\right):\left\{I_{n}\right\} \in \mathfrak{I}\right\}
$$

Berikut ini disajikan beberapa sifat ukuran luar suatu himpunan.

\section{Teorema 1}

(i). Jika $A, B \subset \mathfrak{R}$ dengan $A \subset B$, maka $\mu^{*}(A) \leq \mu^{*}(B)$

(ii). Jika $A \subset \mathfrak{R}$ dan $A$ singleton, maka $\mu^{*}(A)=0$

Akibat Teorema 1 (ii), jika $A \subset \mathfrak{R}$ dan $A$ terhitung (countable), maka $\mu^{*}(A)=0$.

\section{Teorema 2}

Jika $A$ berupa selang, maka $\mu^{*}(A)=l(A)$.

\section{Definisi 6}

Himpunan $E \subset \mathfrak{R}$ dikatakan terukur Lebesgue jika untuk setiap himpunan $A \subset \mathfrak{R}$ berlaku :

$$
\mu^{*}(A)=\mu^{*}(A \cap E)+\mu^{*}\left(A \cap E^{c}\right)
$$

Telah diketahui bahwa $A=(A \cap E) \cup\left(A \cap E^{c}\right)$ dan $\mu^{*}$ bersifat sub aditif, yaitu 
$\mu^{*}(A) \leq \mu^{*}(A \cap E)+\mu^{*}\left(A \cap E^{c}\right)$, karena itu definisi 6 di atas cukup ditulis sebagai : Himpunan $E \subset \mathfrak{R}$ dikatakan terukur Lebesgue jika untuk setiap himpunan $A \subset \Re$ berlaku $\mu^{*}(A) \geq \mu^{*}(A \cap E)+\mu^{*}\left(A \cap E^{c}\right)$.

Untuk selanjutnya dengan himpunan terukur dimaksudkan adalah himpunan terukur Lebesgue.

\section{Teorema 3}

(i). Jika $E$ merupakan himpunan terukur, maka $E^{c}$ juga himpunan terukur.

(ii). $\phi$ dan $\Re$ masing-masing himpunan terukur.

(iii) Jika $\mu^{*}(A)=0$, maka $A$ himpunan terukur.

(iv) Jika $E_{1}, E_{2}$ masing-masing merupakan himpunan terukur, maka $E_{1} \cup E_{2}$ juga himpunan terukur.

\section{Teorema 4}

Setiap interval adalah terukur.

\section{Teorema 5}

Jika $A_{1}, A_{2}, \ldots, A_{n}$ himpunan-himpunan terukur yang saling asing, maka

$$
\mu^{*}\left(\bigcup_{i=1}^{n} A_{i}\right)=\sum_{i=1}^{n} \mu^{*}\left(A_{i}\right)
$$

Berdasarkan pada Teorema 2.2.1.3 (i) dan (iv) diperoleh bahwa $\Sigma$, yaitu koleksi semua himpunan terukur (Lebesgue), merupakan aljabar himpunan pada $\mathfrak{R}$. Lebih lanjut dapat dibuktikan bahwa $\Sigma$ merupakan suatu aljabar$\sigma$ (aljabar-sigma) himpunan pada $\mathfrak{R}$.

Jika $\Sigma$ aljabar (aljabar- $\sigma$ ) himpunan pada $X$ dan $E \in \Sigma$ maka $\sum_{E}=\left\{E \cap A: A \in \sum\right\}$ merupakan aljabar (aljabar$\sigma)$ himpunan pada $E$, terlihat bahwa $\Sigma_{E} \subset \sum$.

\section{Definisi 7}

Ukuran Lebesgue $\mu$ adalah suatu fungsi dari $\Sigma$ ke $\mathfrak{R}$ dengan $\mu(A)=\mu^{*}(A)$ untuk setiap $A \in \sum$. Suatu sifat " $P$ " dikatakan berlaku h.d. pada himpunan $X \subset \Re$ jika untuk setiap himpunan $A \subset X$ dengan $\mu(A)=0$ sehingga " $P$ " berlaku pada $X$ - $A$.

\section{Definisi 8}

Suatu fungsi bernilai riil yang diperluas $f$, yaitu $f: A \rightarrow \Re$ dikatakan terukur Lebesgue pada $A$ atau terukur pada $A \in \sum$ jika himpunan $\{x \in A: f(x)>\alpha\}$ terukur untuk setiap bilangan riil $\alpha$.

\section{Integral Lebesgue}

Definisi 9

Misalkan $E \subset \mathfrak{R}$ suatu himpunan sebarang fungsi $\chi_{E}: \Re \rightarrow \bar{\Re}$ dinamakan fungsi karakteristik dari $E$ jika :

$$
\chi_{E}(x)=\left\{\begin{array}{cc}
1, & x \in E \\
0, & x \notin E
\end{array}\right.
$$

disebut fungsi karakteristik (characteristic function) pada E.

\section{Definisi 10}

Diberikan $\varphi:[a, b] \rightarrow \mathfrak{R}$ disebut fungsi langkah (step function) jika ada selang-selang $I_{1}, I_{2}, \ldots ., I_{n}$ yang saling asing $I_{i} \cap I_{j}=\phi$ untuk $i \neq j$ dan terdapat bilangan $c_{1}, c_{2}, \ldots, c_{n}$ sehingga :

$$
\begin{aligned}
& {[a, b] }=\bigcup_{k=1}^{n} I_{k} \text { ada, } \quad \varphi(x)=\left\{\begin{array}{cc}
c_{k}, & x \in I_{k} \\
0, & x \notin I_{k}
\end{array}\right. \\
& \text { Jadi } \varphi(x)=\sum_{i=1}^{n} c_{k} \chi_{I_{k}} . \quad \text { Sehingga untuk }
\end{aligned}
$$
$x \in[a, b]=\bigcup_{k=1}^{n} I_{k}$, maka ada tepat $I$ sehingga $x \in I_{i}$, maka $\varphi(x)=\sum_{k=1}^{n} c_{k} \chi_{I_{k}}(x)=c_{i} \chi_{I_{i}}(x)=c_{i} \cdot 1=c_{i}$.

\section{Definisi 11}

Jika $(X, \mathscr{A}, \mu)$ ruang ukuran, fungsi $\varphi: X \rightarrow \bar{\Re}$ disebut fungsi sederhana (simple function) pada $\mathrm{X}$, jika terdapat bilangan $c_{1}, c_{2}, \ldots, c_{n}$ dan himpunan terukur $E_{1}, E_{2}, \ldots, E_{n}$, sedemikian sehingga :

$$
X=\bigcup_{k=1}^{n} E_{k} \quad \text { dan } \quad \varphi(x)=\sum_{k=1}^{n} c_{k} \chi_{E_{k}}
$$

Jika $E \subset \mathscr{A}$ maka $\varphi(x)=\sum_{k=1}^{n} c_{k} \chi_{\left(E \cap E_{k}\right)}$,juga

merupakan fungsi sederhana pada $E$. Lebih lanjut jika $E_{k} \cap E_{l}=\phi, \forall k \neq l$, maka fungsi sederhana

$\varphi(x)=\sum_{k=1}^{n} c_{k} \chi_{E_{k}}(x)$ disebut fungsi sederhana bentuk

kanonik.

\section{Definisi 12}

Diberikan $\varphi: \Re \rightarrow \bar{\Re} \quad$ fungsi sederhana dengan $\varphi=\sum_{i=1}^{n} c_{i} \chi_{E_{i}}$ dan $E \in \sum$. Integral Lebesgue fungsi sederhana $\varphi$ pada $E$ didefinisikan sebagai bilangan $(L) \int_{E} \varphi=(L) \int_{E} \varphi d \mu=\sum_{i=1}^{n} c_{i} \mu\left(E_{i} \cap E\right)$.

\section{Definisi 13}

Diberikan $f: \Re \rightarrow \bar{\Re}$ fungsi terbatas dan $E$ himpunan terukur. Integral Lebesgue atas dan bawah fungsi $f$ pada $E$ didefinisikan oleh

$$
\int_{E}^{-} f=\inf \left\{\int_{E} \varphi: \varphi \geq f, \varphi \text { fungsi sederhana }\right\}
$$




$$
\int_{E}^{-} f=\sup \left\{\int_{E} \varphi: \varphi \leq f, \varphi \text { fungsi sederhana }\right\}
$$

Jika kedua integral ini bernilai sama dan hingga, maka dikatakan bahwa fungsi $f$ terintegral Lebesgue pada $E$ dan nilainya ditulis dengan $\int_{E} f=\int_{E} f d \mu$. Jika $E=[a, b]$, bilangan $\int_{E} f$ biasa ditulis $\int_{a}^{b} f$, jadi $\int_{E} f=\int_{a}^{b} f$.

\section{Definisi 14}

Diberikan $f:[a, b] \rightarrow \bar{\Re}$ fungsi terukur nonnegatif. Integral Lebesgue fungsi $f$ pada $[\mathrm{a}, \mathrm{b}]$ didefinisikan oleh : $\int_{a}^{b} f=\sup \left\{\int_{a}^{b} u: 0 \leq u \leq f, u\right.$ fungsi terukur terbatas pada $\left.[a, b]\right\}$

Jika $\int_{a}^{b} f$ hingga maka $f$ dikatakan terintegral Lebesgue pada $[\mathrm{a}, \mathrm{b}]$.

\section{Teorema 6}

Diberikan $f, g$ fungsi terukur nonnegatif yang didefinisikan pada $[a, b]$, serta $A$ dan $B$ merupakan himpunan bagian terukur di dalam $[a, b]$. Dipenuhi :

a. Untuk semua $k>0, \int_{a}^{b} k f=k \int_{a}^{b} f$,

Lebih lanjut, jika $f$ terintegral Lebesgue pada [a,b] maka $k f$ terintegral pada $[a, b]$.

b. Berlaku $\int_{a}^{b}(f+g)=\int_{a}^{b} f+\int_{a}^{b} g$

Lebih lanjut, jika $f$ dan $g$ terintegral Lebesgue pada $[a, b]$ maka $f+g$ terintegral pada $[a, b]$.

\section{Definisi 15}

Fungsi terukur $f$ dikatakan terintegral Lebesgue pada himpunan terukur $E$, jika fungsi-fungsi nonnegatif $f^{+}$ dan $f^{-}$masing-masing terintegral Lebesgue pada $E$ dan didefinisikan :

$$
\int_{E} f d \mu=\int_{E} f^{+} d \mu-\int_{E} f^{-} d \mu
$$

Selanjutnya $f^{+}$bagian positif fungsi $f$ didefinisikan sebagai fungsi $f^{+}(x)=\max \{f(x), 0\} \quad$ dan $f^{-}$ bagian negatif fungsi $f$ didefinisikan sebagai fungsi $f^{-}(x)=\max \{-f(x), 0\}$. Jika $f$ terukur maka $f^{+}$dan $f^{-}$juga terukur. Diperoleh bahwa $f=f^{+}-f^{-}$dan $|f|=f^{+}+f^{-}$. Fungsi terukur $f:[a, b] \rightarrow \Re$ terintegral
Lebesgue pada $[a, b]$ jika dan hanya jika $|f|$ terintegral Lebesgue pada $[a, b]$. Dalam hal ini $f^{+}$dan $f^{-}$ terintegral Lebesgue pada $[a, b]$ dan intgeral Lebesgue $f$ pada $\quad[a, b]$ didefinisikan sebagai $\int_{a}^{b} f d \mu=\int_{a}^{b} f^{+} d \mu-\int_{a}^{b} f^{-} d \mu$

\section{Teorema 7}

Diberikan $f$ dan $g$ fungsi terintegral Lebesgue pada $[a, b]$ serta $A$ dan $B$ merupakan himpunan bagian terukur dari $[a, b]$, dipenuhi :

a. $\quad k \quad f$ terintegral Lebesgue pada $[a, b]$ dan $\int_{a}^{b} k f=k \int_{a}^{b} f$ untuk setiap $k$.

b. $f+g$ terintegral Lebesgue pada $[a, b]$ dan $\int_{a}^{b}(f+g)=\int_{a}^{b} f+\int_{a}^{b} g$

c. jika $f \leq g$ h.d. pada $[a, b]$, maka $\int_{a}^{b} f \leq \int_{a}^{b} g$

d. jika $f=g$ h.d. pada $[a, b]$, maka $\int_{a}^{b} f=\int_{a}^{b} g$

e. berlaku $\left|\int_{a}^{b} f\right| \leq \int_{a}^{b}|f|$

f. jika $A$ dan $B$ saling asing, maka $\int_{A \cup B} f=\int_{A} f+\int_{B} f$.

\section{HASIL DAN PEMBAHASAN}

\section{Perluasan Integral Lebesgue}

Pada bagian ini akan disajikan pengertian Perluasan Integral Lebesgue atau disebut Integral- $E L$ dan beberapa sifat yang berlaku padanya. Integral- $E L$ merupakan suatu perluasan integral Lebesgue. Untuk selanjutnya $f \in L\left(\bar{I}_{k}\right)$ dimaksudkan bahwa $f$ terintegral Lebesgue pada $\bar{I}_{k}$ dan $(L) \int_{\bar{I}_{k}} f d \mu$ menyatakan nilai integral Lebesgue fungsi $f$ pada $\bar{I}_{k}, \mu$ ukuran Lebesgue dan $\bar{I}_{k}$ suatu selang

\section{Definisi 16}

Suatu fungsi $f:[a, b] \rightarrow \bar{\Re}$ dikatakan terintegral- $E L$ pada $[a, b]$ jika terdapat barisan selang yang tidak tumpang tindih $\left\{I_{k}\right\}$ di dalam $[a, b]$ sehingga

$$
\mu\left([a, b]-\bigcup I_{k}\right)=0, \quad f \in L\left(\bar{I}_{k}\right)
$$


untuk setiap $k$ dan $A=\sum_{k=1}^{\infty}(L) \int_{\bar{I}_{k}} f d \mu$ berhingga. Untuk selanjutnya bilangan $A=\sum_{k=1}^{\infty}(L) \int_{\bar{I}_{k}} f d \mu \quad$ di Bilangan $A$ tersebut disebut nilai integral-EL fungsi $f$ dalam Definisi 16 disebut nilai integral-EL fungsi $f$ pada pada $[a, b]$, ditulis :

$(E L) \int_{\bar{I}_{k}} f d \mu=\sum_{k=1}^{\infty}(L) \int_{\bar{I}_{k}} f d \mu$

$[a, b]$ dan ditulis $(E L) \int_{a}^{b} f$, jadi

$$
(E L) \int_{a}^{b} f=\sum_{k=1}^{\infty}(L) \int_{\bar{I}_{k}} f d \mu
$$

\section{Teorema 8 (Ketunggalan)}

Jika $f$ terintegral-EL $[a, b]$, maka nilai integral $A$ yang dimaksud di dalam Definisi 16 adalah tunggal.

Bukti :

Andaikan ada dua nilai $A_{1}$ dan $A_{2}$ seperti di dalam Definisi 16 berarti :

1. Terdapat barisan selang yang tidak tumpang tindih $\left\{I_{k}\right.$ \} di dalam $[a, b]$ sehingga

$$
\begin{aligned}
& \mu\left([a, b]-\bigcup I_{k}\right)=0, f \in L\left(\bar{I}_{k}\right) \text { untuk setiap } k \text { dan } \\
& A_{1}=(E L) \int_{\bar{I}_{k}} f d \mu=\sum_{k=1}^{\infty}(L) \int_{\bar{I}_{k}} f d \mu
\end{aligned}
$$

2. Terdapat barisan selang yang tidak tumpang tindih

$$
\begin{aligned}
& \left\{J_{l}\right\} \quad \text { di } \quad \text { dalam } \quad[a, b] \text { sehingga } \\
& \mu\left([a, b]-\bigcup J_{l}\right)=0, f \in L\left(\bar{J}_{l}\right) \text { untuk setiap } k \text { dan } \\
& A_{2}=(E L) \int_{\bar{I}_{k}} f d \mu=\sum_{k=1}^{\infty}(L) \int_{\bar{J}_{l}} f d \mu
\end{aligned}
$$

Dibentuk barisan selang $\left\{H_{k l}\right\}$ dengan $H_{k l}=I_{k} \cap J_{l}$ untuk setiap $k$ dan $l$. Jelas bahwa $\left\{H_{k l}\right\}$ merupakan barisan himpunan terukur yang tidak tumpang tindih, sebab

$$
\begin{gathered}
\mu\left([a, b]-\bigcup_{k} \bigcup_{l} H_{k l}\right)=\mu\left([a, b]-\bigcup_{k}\left(I_{k} \cap J_{l}\right)\right) \\
=\mu\left([a, b]-\bigcup_{k}\left(I_{k} \cap\left(\bigcup_{l} J_{l}\right)\right)\right) \\
=\mu\left([a, b]-\bigcup_{k} I_{k}\right)=0
\end{gathered}
$$

Diperoleh :

$$
\begin{aligned}
& \left|A_{1}-A_{2}\right|=\left|\sum_{k=1}^{\infty}(L) \int_{I_{k}} f d \mu-\sum_{l=1}^{\infty}(L) \int_{J_{l}} f d \mu\right| \\
& =\left|\sum_{k=1}^{\infty} \sum_{l=1}^{\infty}(L) \int_{I_{k} \cap J_{l}} f d \mu-\sum_{k=1}^{\infty} \sum_{l=1}^{\infty}(L) \int_{I_{k} \cap J_{l}} f d \mu\right|=0
\end{aligned}
$$

Jadi $A_{1}=A_{2}$. Sehingga diperoleh bahwa nilai A adalah tunggal .

Himpunan semua fungsi yang terintegral-EL pada $[a, b]$ ditulis $E L[a, b]$. Akibat langsung dari Definisi 16 adalah bahwa setiap fungsi $f$ yang terintegral Lebesgue pada $[a, b]$ adalah terintegral-EL pada $[a, b]$. Seperti dinyatakan dalam teorema berikut ini.

\section{Teorema 9}

Jika fungsi $f$ terintegral Lebesgue pada $[a, b]$, maka $f$ terintegral-EL pada $[a, b]$.

Bukti :

Diberikan fungsi $f$ terintegral Lebesgue pada $[a, b]$. Dibentuk barisan $\left\{I_{k}\right\}$ dengan cara sebagai berikut $I_{k}=\left[a+\frac{b-a}{k-1}, a+\frac{b-a}{k}\right]$ untuk setiap $k=1,2, \ldots \ldots$

Diperoleh $\mu\left([a, b]-\bigcup I_{k}\right)=0, \quad f \in L\left(\bar{I}_{k}\right)$ untuk setiap $k$ dan $(E L) \int_{a}^{b} f=\sum_{k=1}^{\infty}(L) \int_{I_{k}} f d \mu=(L) \int_{a}^{b} f d \mu$ berhingga.

Jadi fungsi terintegral-EL pada $[a, b]$.

\section{Teorema 10}

Jika fungsi $f$ terintegral-EL pada $[a, b]$ dan $f=g$ h.d. pada $[a, b]$, maka $g$ terintegral-EL pada $[a, b]$ dan $(E L) \int_{a}^{b} g=(E L) \int_{a}^{b} f$.

Bukti :

$F$ terintegral-EL pada $[a, b]$ berarti ada barisan selang yang tidak tumpang tindih $\left\{I_{k}\right\}$ di dalam $[a, b]$ sehingga $\mu\left([a, b]-\bigcup I_{k}\right)=0, \quad f \in L\left(\bar{I}_{k}\right) \quad$ untuk setiap $k$ dan $(E L) \int_{a}^{b} f=\sum_{k=1}^{\infty}(L) \int_{\bar{I}_{k}} f d \mu$ berhingga.

Karena $g=f \quad$ h.d. pada $[a, b]$ dan $f \in L\left(\bar{I}_{k}\right)$ untuk setiap $k$ maka $g=f$ h.d. pada $I_{k}$ untuk setiap $k$, sehingga diperoleh $\quad g \in L\left(\bar{I}_{k}\right) \quad$ dan $(L) \int_{\bar{I}_{k}} g d \mu=(L) \int_{\bar{I}_{k}} f d \mu \quad$ untuk setiap $k$. Jadi $(E L) \int_{a}^{b} g=\sum_{k=1}^{\infty}(L) \int_{\bar{I}_{k}} g d \mu=\sum_{k=1}^{\infty}(L) \int_{\bar{I}_{k}} f d \mu=(E L) \int_{a}^{b} f$. 
Fungsi nonnegatif yang terintegral-EL ternyata juga terintegral Lebesgue pada selang yang sama, seperti dinyatakan dalam teorema berikut ini.

\section{Teorema 11}

Jika $f$ terintegral-EL pada $[a, b]$ dan $f \geq 0$ h.d. pada $[a, b]$, maka $f$ terintegral Lebesgue pada $[a, b]$.

Bukti :

$f$ terintegral-EL pada $[a, b]$ berarti ada barisan selang yang tak tumpang tindih $\left\{I_{k}\right\}$ di dalam $[a, b]$ sehingga $\mu\left([a, b]-\bigcup I_{k}\right)=0, \quad f \in L\left(\bar{I}_{k}\right) \quad$ untuk setiap $k$ dan $(E L) \int_{a}^{b} f=\sum_{k=1}^{\infty}(L) \int_{\bar{I}_{k}} f d \mu$ berhingga.

Untuk setiap $n$ dibentuk fungsi $f_{n}$ dengan rumus :

$$
f_{n}(x)=\left\{\begin{array}{cc}
f(x) & \text {, untuk } x \in \bar{I}_{k} \\
0 & \text { untuk } x \notin \bar{I}_{k}
\end{array}\right.
$$

Terlihat bahwa $\left\{f_{n}\right\}$ naik monoton h.d. pada $[a, b]$, $\lim _{n \rightarrow \infty} f_{n}(x)=f(x) \quad$ h.d. pada $[a, b]$ dan $f_{n} \in L\left(\bar{I}_{k}\right)$ untuk setiap $k$.

Menurut Teorema Kekonvergenan Monoton Lebesgue maka $f \in L[a, b]$ dan

$$
(L) \int_{a}^{b} f d \mu=\lim _{n \rightarrow \infty}(L) \int_{a}^{b} f_{n} d \mu=\sum_{k=1}^{\infty}(L) \int_{\bar{I}_{k}} f d \mu
$$

berhingga. Jadi $f \in L[a, b]$.

Dalam Teorema berikut ini dinyatakan bahwa integral-EL memenuhi sifat linear.

\section{Teorema 12}

Jika $f, g$ terintegral-EL pada $[a, b]$ dan $\alpha \in R$, maka :

1. $\alpha f$ terintegral-EL pada $[a, b]$ dan

$$
(E L) \int_{a}^{b} \alpha f=\alpha(E L) \int_{a}^{b} f
$$

2. $f+g$ terintegral-EL pada $[a, b]$ dan

Bukti :

$$
(E L) \int_{a}^{b}(f+g)=(E L) \int_{a}^{b} f+(E L) \int_{a}^{b} g
$$

1. Jika $f$ terintegral-EL pada $[a, b]$ berarti ada barisan selang yang tidak tumpang tindih $\left\{I_{k}\right\}$ di dalam $[a, b]$ sehingga $\quad \mu\left([a, b]-\bigcup I_{k}\right)=0, \quad f \in L\left(\bar{I}_{k}\right) \quad$ untuk setiap $k$ dan $(E L) \int_{a}^{b} f=\sum_{k=1}^{\infty}(L) \int_{\bar{I}_{k}} f d \mu$ berhingga.

Untuk setiap $k, f \in L\left(I_{k}\right) \Rightarrow \alpha f \in L\left(I_{k}\right)$ dan (L) $\int_{I_{k}} \alpha f d \mu=\alpha(L) \int_{I_{k}} f d \mu$ diperoleh

$$
\begin{aligned}
(E L) \int_{a}^{b} \alpha f & =\sum_{k=1}^{\infty}(L) \int_{\bar{I}_{k}} \alpha f d \mu=\alpha \sum_{k=1}^{\infty}(L) \int_{\underline{I}_{k}} f d \mu \\
& =\alpha(E L) \int_{a}^{b} f
\end{aligned}
$$

berhingga.

Jadi $\alpha f \in E L[a, b]$.

2. Jika $g$ terintegral-EL pada $[a, b]$ berarti ada barisan selang yang tidak tumpang tindih $\left\{J_{k}\right\}$ di dalam $[a, b]$ sehingga $\mu\left([a, b]-\bigcup J_{l}\right)=0, \quad g \in L\left(\bar{J}_{l}\right) \quad$ untuk setiap $l$ dan $(E L) \int_{a}^{b} g=\sum_{l=1}^{\infty}(L) \int_{J_{l}} g d \mu$ berhingga.

Dibentuk barisan selang yang tidak tumpang tindih $\left\{H_{k l}\right\}$ dengan $H_{k l}=I_{k} \cap J_{l}$ seperti pada Teorema 8

$\mu\left([a, b]-\bigcup_{k} \bigcup_{l} H_{k l}\right)=0$,

$f, g \in L\left(H_{k l}\right) \Rightarrow f+g \in L\left(H_{k l}\right)$ untuk setiap $k$ dan $l$

$$
\begin{gathered}
(E L) \int_{a}^{b}(f+g)=\sum_{k=1}^{\infty} \sum_{l=1}^{\infty}(L) \int_{H_{k l}}(f+g) d \mu \\
=\sum_{k=1}^{\infty} \sum_{l=1}^{\infty}(L) \int_{I_{k} \cap J_{l}}(f+g) d \mu \\
=\sum_{k=1}^{\infty} \sum_{l=1}^{\infty}\left((L) \int_{I_{k} \cap J_{l}} f d \mu+(L) \int_{I_{k} \cap J_{l}} f d \mu\right) \\
=\sum_{k=1}^{\infty} \sum_{l=1}^{\infty}(L) \int_{I_{k} \cap J_{l}} f d \mu+\sum_{k=1}^{\infty} \sum_{l=1}^{\infty}(L) \int_{I_{k} \cap J_{l}} g d \mu \\
=\sum_{k=1}^{\infty}(L) \int_{I_{k}} f d \mu+\sum_{l=1}^{\infty}(L) \int_{J_{l}} g d \mu
\end{gathered}
$$

$$
(E L) \int_{a}^{b}(f+g)=(E L) \int_{a}^{b} f+(E L) \int_{a}^{b} g
$$

Jadi $(f+g) \in E L[a, b]$.

\section{Teorema 13}

Jika $f, g$ terintegral-EL pada $[a, b]$ dan $f \leq g$ h.d. pada $[a, b]$, maka $(E L) \int_{a}^{b} f \leq(E L) \int_{a}^{b} g$.

Bukti :

$f \leq g$ h.d. pada $[a, b]$ berakibat $g-f \geq 0$ h.d. pada $[a, b], f, g$ terintegral-EL pada $[a, b]$ berakibat $g-f$ 
terintegral-EL pada $[a, b], \quad$ sehingga diperoleh $(E L) \int^{b}(g-f) \geq 0$ atau $(E L) \int^{b} f \leq(E L) \int^{b} g$

\section{Teorema 14}

Jika $f$ terintegral-EL pada $[a, b]$ dan $[u, v] \subseteq[a, b]$, maka $f$ terintegral-EL pada $[u, v]$.

Bukti :

$f$ terintegral-EL pada $[a, b]$ berarti ada barisan selang yang tidak tumpang tindih $\left\{I_{k}\right\}$ di dalam $[a, b]$ sehingga $\mu\left([a, b]-\bigcup I_{k}\right)=0, f \in L\left(\bar{I}_{k}\right)$ untuk setiap $k$ dan $(E L) \int_{a}^{b} f=\sum_{k=1}^{\infty}(L) \int_{\bar{I}_{k}} f d \mu$ berhingga.

Dibentuk barisan $\left\{J_{k}\right\}$ dengan $J_{k}=I_{k} \cap[u, v]$ untuk setiap $k, J_{k}=\phi$ atau $J_{k}=I_{k}$ atau $J_{k}=I_{N}^{\prime \prime}$ dengan $I_{N}=I_{N}^{\prime} \cup I_{N}^{\prime \prime} \quad$ untuk suatu $N, \mu\left([u, v]-\bigcup J_{k}\right)=0$, seba $\mu\left([u, v]-\bigcup I_{k}\right)=0$ dan $[a, b]-\bigcup I_{k} \subseteq[u, v]-\bigcup J_{k}$.

Karena $f \in L\left(\bar{I}_{k}\right)$ untuk setiap k berakibat $f \in L\left(\bar{J}_{k}\right)$ untuk setiap $k$.

Terdapat dua kemungkinan :

i) Jika $\left\{J_{k}\right\}$ barisan berhingga, maka

$$
\begin{aligned}
& \sum_{k=1}^{N}(L) \int_{\bar{I}_{k}} f d \mu \text { berhingga } \\
& f \in L[u, v] \subseteq E L[u, v]
\end{aligned}
$$

diperoleh

ii) Jika $\left\{J_{k}\right\}$ barisan tak berhingga, maka ada bilangan asli $N$ sehingga

$$
\begin{aligned}
\sum_{k=1}^{\infty}(L) \int_{I_{k}} f d \mu & =\sum_{k=1}^{N-1}(L) \int_{I_{k}} f d \mu+(L) \int_{I_{N}^{\prime}} f d \mu \\
& +(L) \int_{I_{N}^{\prime \prime}} f d \mu+\sum_{k=N+1}^{\infty}(L) \int_{J_{k}} f d \mu
\end{aligned}
$$

diperoleh $\sum_{k=N+1}^{\infty}(L) \int_{J_{k}} f d \mu$ berhingga, sehingga

$f$ terintegral-EL pada $[u, v]$.

Jadi dari (i) dan (ii), maka dapat diperoleh

$$
f \in E L[a, b] \text {. }
$$

\section{Teorema 15}

Jika $f \in E L[a, b]$ dan $a<c<b$, maka

$$
(E L) \int_{a}^{b} f=(E L) \int_{a}^{c} f+(E L) \int_{c}^{b} f \text {. }
$$

Bukti :

$f$ terintegral-EL pada $[a, b]$ berarti ada barisan selang yang tidak tumpang tindih $\left\{I_{k}\right\}$ di dalam $[a, b]$ sehingga $\mu\left([a, b]-\bigcup I_{k}\right)=0, f \in L\left(\bar{I}_{k}\right) \quad$ untuk setiap $k$ dan $(E L) \int_{a}^{b} f=\sum_{k=1}^{\infty}(L) \int_{I_{k}} f d \mu$ berhingga.
Karena $[a, c] \subseteq[a, b]$ diperoleh $f \in E L[a, c]$

Karena $[c, b] \subseteq[a, b]$ diperoleh $f \in E L[c, b]$

Diambil barisan $\left\{A_{k}\right\}$ dan $\left\{B_{k}\right\}$ dengan $A_{k}=I_{k} \cap[a, c]$ dan $B_{k}=I_{k} \cap[c, b]$ sehingga $I_{k}=A_{k} \cup B_{k}$ untuk setiap

$k$ dan diperoleh $\mu\left([a, c]-\bigcup A_{k}\right)=0 \quad$ dan $\mu\left([c, b]-\bigcup B_{k}\right)=0$

$$
\begin{aligned}
& f \in L\left(A_{k}\right) \text { dan } f \in L\left(B_{k}\right) \\
& (E L) \int_{a}^{b} f=\sum_{k=1}^{\infty}(L) \int_{I_{k}} f d \mu=\sum_{k=1}^{\infty}(L) \int_{A_{k} \cup B_{k}} f d \mu \\
& (E L) \int_{a}^{b} f=\sum_{k=1}^{\infty}\left((L) \int_{A_{k}} f d \mu+(L) \int_{B_{k}} f d \mu\right) \\
& (E L) \int_{a}^{b} f=\sum_{k=1}^{\infty}(L) \int_{A_{k}} f d \mu+\sum_{k=1}^{\infty}(L) \int_{B_{k}} f d \mu \\
& (E L) \int_{a}^{b} f=(E L) \int_{a}^{c} f+(E L) \int_{c}^{b} f .
\end{aligned}
$$

\section{Teorema 16}

Jika $f$ fungsi terintegral-EL pada $[a, b]$, maka untuk setiap bilangan positif $\varepsilon$ terdapat bilangan positif $\delta$ sehingga untuk setiap himpunan $A \subseteq[a, b]$ dengan $\mu(A)<\delta$ berlaku bahwa $\left|(E L) \int_{A} f\right|<\varepsilon$.

Bukti :

$f$ terintgeral-EL pada $[a, b]$ berarti terdapat barisan selang yang tidak tumpang tindih $\left\{I_{k}\right\}$ di dalam $[a, b]$ sehingga $\mu\left([a, b]-\bigcup_{k} I_{k}\right)=0, \quad f$ terintegral Lebesgue pada $I_{k}$ untuk setiap $k$ dan $(E L) \int_{a}^{b} f=\sum_{k=1}^{\infty}(L) \iint_{I_{k}} f d \mu$ berhingga.

Diambil sebarang bilangan $\varepsilon>0, \quad \sum_{k=1}^{\infty}(L) \int_{I_{k}} f d \mu$ berhingga berarti terdapat bilangan asli $n_{0}$ sehingga untuk setiap $k \geq n_{0}$ berlaku $\left|\sum_{k=n_{0}}^{\infty}(L) \int_{I_{k}} f d \mu\right|<\frac{\varepsilon}{2}$.

$f$ terintegral Lebesgue pada $I_{k}$ untuk setiap $k$, berarti terdapat bilangan $\delta_{k}>0$ sehingga jika $A_{k} \subseteq I_{k}$ dengan $\mu\left(A_{k}\right)<\delta_{k}$ berakibat $\left|(L) \int_{A_{k}} f d \mu\right|<\frac{\varepsilon}{2 n_{0}}$.

Dipilih $\delta=\min \left\{\delta_{1}, \delta_{2}, \ldots, \delta_{n_{0}}\right\}$ dan diambil sembarang $A \subseteq[a, b]$ dengan $\mu(A)<\delta \quad$ sehingga diperoleh $\left|(L) \int_{A_{k}} f d \mu\right|<\frac{\varepsilon}{2 n_{0}}$

Diperoleh 


$$
\mu\left(A \cap I_{k}\right)<\delta \text { sehingga }\left|(L) \int_{A \cap I_{k}} f d \mu\right|<\frac{\varepsilon}{2 n_{0}} .
$$

Jadi :

$$
\begin{aligned}
\left|(E L) \int_{A} f\right| & =\left|\sum_{k=1}^{\infty}(L) \int_{A \cap I_{k}} f d \mu\right| \\
& \leq \sum_{k=1}^{n_{0}}\left|(L) \int_{A \cap I_{k}} f d \mu\right|+\left|\sum_{k=n_{0}+1}^{\infty}(L) \int_{A \cap I_{k}} f d \mu\right| \\
& <\sum_{k=1}^{n_{0}} \frac{\varepsilon}{2 n_{0}}+\left|\sum_{k=n_{0}+1}^{\infty}(L) \int_{I_{k}} f d \mu\right| \\
\left|(E L) \int_{A} f\right| & <\frac{\varepsilon}{2}+\frac{\varepsilon}{2}=\varepsilon
\end{aligned}
$$

Teorema berikut ini menunjukan bahwa $L[a, b]$ merupakan himpunan bagian sejati di dalam $E L[a, b]$.

\section{Teorema 17}

Jika $f \in E L[a, b]$ dan $f \in L[a, b]$, maka ada $[c, d] \subset[a, b]$ sehingga $f \in E L[c, d]$ dan $f \notin L[c, d]$.

Bukti :

Andaikan untuk setiap $[x, y] \subset[a, b]$ berlaku $f \in L[x, y]$ akan ditunjukan bahwa $f \notin L[a, b]$

ambil sebarang $[c, d] \subset[a, b]$ Diperoleh $f \in L[c, d]$

Karena $[a, c] \subset[a, b], \quad[d, b] \subset[a, b] \quad$ diperoleh juga $f \in L[a, c]$ dan $f \in L[d, b]$

Berarti $f \in L[a, b]$

Ini kontradiksi dengan $f \notin L[a, b]$.

Dengan demikian diperoleh bahwa $f \in E L[c, d]$ dan $f \notin L[c, d]$.

\section{KESIMPULAN}

Berdasarkan hasil pembahasan dari bab-bab sebelumnya dapat disimpulkan bahwa

1. Integral-EL merupakan perluasan dari integral Lebesgue yang dinotasikan dengan :

$$
(E L) \int_{a}^{b} f d \mu=\sum_{k=1}^{\infty}(L) \int_{\bar{I}_{k}} f d \mu .
$$

2. Jika $f$ terintegral Lebesgue maka $f$ terintegral-EL, tetapi sebaliknya belum pasti $(f \in L[a, b] \subset f \in E L[a, b])$. Secara umum sifatsifat dasar yang berlaku pada integral Lebesgue berlaku juga pada integral-EL.

3. Beberapa sifat-sifat dasar yang berlaku pada integralEL, sebagai berikut : a). Jika $f$ terintegral-EL pada $[a, b]$, maka nilai integral- $E L$ fungsi $f$ pada $\quad[a, b]$ tunggal.

b). Fungsi $f$ terintegral-EL pada $[a, b]$ jika dan hanya jika $f$ terintegral- $H K$ pada $[a, b]$.

c). Jika fungsi $f$ terintegral-EL pada $[a, b]$ dan $f=g$ h.d pada $[a, b]$ maka $g$ terintegral$E L$ pada $[a, b]$ dan $(E L) \int_{a}^{b} f=(E L) \int_{a}^{b} g$.

d). Jika $f$ terintegral-EL pada $[a, b]$ dan $f \geq 0$ h.d pada $[a, b]$ maka $f$ terintegral lebesgue pada $[a, b]$.

e). Jika $f$, $g$ terintegral- $E L$ pada $[a, b]$ dan $f \leq g$ h.d pada $[a, b]$ maka $(E L) \int_{a}^{b} f \leq(E L) \int_{a}^{b} g$.

f). Jika $f$ terintegral-EL pada $[a, b]$ dan $[u, v] \subset[a, b]$ maka $f$ terintegral-EL pada $[u, v]$.

g). Jika $f \in E L[a, b]$ dan $a<c<b$, maka $(E L) \int_{a}^{b} f=(E L) \int_{a}^{c} f+(E L) \int_{c}^{b} f$.

\section{DAFTAR PUSTAKA}

De, Barra, G., (1981), Measure Theory And Integration., Third Avenue., John Wiley and Sons. Inc., New York.

Gordon, R, A., (1994), The Integrals Of Lebesgue, Denjoy, Perron, and Henstock., Graduate Studies In Mathematics 4, Volume 4., American Mathematical Society.,USA.

Hutahaean, E., (1989), Analisis Real II, Penerbit Karunika, Universitas Terbuka, Jakarta.

Jain, P. K. and Gupta, V. P., (1986), Lebesgue Measure and Integration. Wiley Eastern Limited, New Delhi.

Royden, H, L., (1989), Real Analysis, Third Edition, Macmillan Publishing Company, New York.

Rudin, W., (1976), Principles Of Mathematical Analysis, Third Edition, Mc Graw-Hill Book Company., Ltd, Singapore.

Soeparna, D., (1999), An Extension of General Lebesgue Integral, Proceeding of the SEAMS-Gadjah Mada Univercity Conference, Yogyakarta.

Wheeden, R, L and Zygmund, A., (1977), Measure and Integral; An Introduction to real Analysis., Marcel Dekker. Inc., New York. 